\title{
LOS “PROTO-ESTADOS” DEL ALTO EGIPTO Y LA UNIFICACIÓN DEL VALLE DEL NILO
}

\author{
Marcelo Campagno*
}

\begin{abstract}
CAMPAGNO, M. Los "proto-Estados" del Alto Egipto y la unificación del valle del Nilo. Rev. do Museu de Arqueologia e Etnologia, São Paulo, 12: 123-141, 2002.
\end{abstract}

\begin{abstract}
RESUMO: A unificação política do vale do Nilo, alcançada pouco antes de 3.000 a.C., foi o resultado da expansão das práticas estatais surgidas no Alto Egito por volta dos anos 3.400 a.C. Inicialmente (Nagada Ic-d), parecem ter tomado forma na região três "proto-Estados", centrados em Hieracompolis, Nagada e Abidos, que confluiriam logo para um único "proto-Estado" no Alto Egito. Durante o mesmo período, também, se verifica uma crescente influência cultural desses núcleos sobre todo o território compreendido entre a primeira catarata do Nilo e o Mar Mediterrâneo. Na fase imediatamente posterior (Nagada IIIa-b), a homogeneização cultural do vale do Nilo daria passagem à integração política, a partir da expansão territorial do "protoEstado" sulino.
\end{abstract}

UNITERMOS: Egito antigo - Proto-Estados - Unificação do Egito-Política egípcia.

I.

En la imagen legada por las corrientes egiptológicas tradicionales, el proceso de unificación política del territorio comprendido entre la primera catarata del Nilo y el mar Mediterráneo - y con él, el de la constitución de una sociedad propiamente estatal - sucedía de un modo bastante súbito. Para unos, se trataba de la conquista de todo ese territorio por parte de una Raza Dinástica venida de lejos y provista de todos los atributos inherentes a la civilización. Para otros, era el resultado de una memorable victoria militar del mítico rey Menes, a resultas de la cual quedarían unidos los dos reinos predinásticos simétricamente dispuestos en el valle y del delta del Nilo.

(*) Universidad de Buenos Aires, Argentina.
Ciertamente, en la actualidad, no se admiten los postulados hiperdifusionistas a partir de los que se sostenía la primera interpretación, así como tampoco suele aceptarse la lectura historicista de los Textos de las Pirámides a partir de la cual se proponía la segunda. En el relevo de esas antiguas posiciones, las interpretaciones contemporáneas tienden a destacar la sensible disparidad de la documentación arqueológica disponible para el norte y el sur, para concluir que los primeros indicios estatales se advierten decididamente en el sur en torno de unos 3400-3300 años a.C. y que la posterior unificación del territorio que tradicionalmente se identifica como Egipto obedece centralmente a la dinámica de expansión de las prácticas estatales surgidas en la región meridional.

Ahora bien, ¿cómo se produce esa expansión? ¿Cuáles son las características de ese proceso que se inicia con la aparición de las primeras prácticas estatales en el sur y que culmina hacia el 3000 a.C. 
con el advenimiento de los monarcas de la Dinastía I y la unificación de un territorio de unos 1300 kilómetros de longitud? En las páginas que siguen, intentaremos proponer algunas consideraciones en torno de esta época "proto-estatal" de la historia egipcia, que resulta crucial para comprender el modo específico en que se consolida la sociedad estatal que se constituye a orillas del Nilo.

\section{II.}

En el valle del Nilo, las primeras prácticas estatales parecen surgir en un clima de recurrentes conflictos, que pueden estar relacionados con las disputas intercomunitarias en el Alto Egipto, en pos de acaparar los bienes de prestigio procedentes de regiones lejanas. Esos bienes de prestigio debían tener una enorme importancia para las élites locales, dado que - en un tipo de sociedades donde el monopolio de la coerción se hallaba ausente - su posesión y ostentación podía constituir uno de los mecanismos básicos para la demarcación de diferencias sociales dentro de las comunidades aldeanas. En ese marco, los intentos por acaparar tales bienes y suprimir la competencia de las comunidades rivales pudieron conducir a un tipo de conflictos que favoreciera la subordinación permanente de los vencidos a los vencedores. La supremacía militar de unas comunidades sobre otras podría haber instituido los primeros vínculos de dominación y la perduración de éstos podría haber desembocado en la consolidación de los primeros lazos de índole estatal, vale decir, lazos que instituían un grupo social provisto del monopolio de la coerción y otro grupo social subordinado al primero (Campagno 2001: 13-31; 2002a: Caps. 5-7).

Ahora bien, lo que parece cobrar forma en el registro arqueológico correspondiente a la subfase Nagada IIc (3400-3300 a.C.) no es la aparición de un único centro regional en el que pudieran advertirse estos cambios sino la constitución de al menos tres entidades sociopolíticas en el Alto Egipto, en las que se registran una serie de transformaciones más o menos simultáneas. En efecto, para aquella época, los núcleos de Hieracómpolis, Nagada y Abidos ofrecen una serie de características que los distinguen de otras localidades de la región y que han permitido suponer que constituyen los primeros "proto-Estados"' del valle del Nilo.

¿Qué testimonios existen acerca de tales "proto-Estados"? En relación con Hieracómpolis, durante la fase Nagada II se advierte la existencia de una compleja división del trabajo y de una élite cuyos miembros eran enterrados en tumbas sensiblemente diferenciadas del resto de la sociedad. En efecto, por una parte, existe evidencia acerca de sitios específicos para la producción de pan y cerveza (Geller 1992: 23-24), que presuponen la presencia de un artesanado especializado.

Asimismo, de Nagada IIb-d data un notable recinto (Hk 29a) que podría tener casi 40m de largo, que presenta estructuras en adobe y madera y que ha sido interpretado como un gran complejo ceremonial (Friedman 1996: 16-35).

Por otra parte, en cuanto a la evidencia funeraria, sobresale indudablemente la llamada Tumba 100 o Tumba Decorada, cuya datación remite a la fase Nagada IIc (Vandier 1952: 561-570; Case y Payne 1962: 5-18; Midant-Reynes 1992: 194-197; Adams y Cialowicz 1997: 36-40). Tal enterramiento no sólo se destaca por sus dimensiones $(5,85 \mathrm{~m}$ de largo $x 2,85 \mathrm{~m}$ de ancho $x 1,50 \mathrm{~m}$ de profundidad) y por el adobe utilizado para revestir sus paredes y un muro interior sino también por la decoración que presentan esos muros. Allí aparece todo un conjunto de representaciones iconográficas que testimonian los conflictos de la época (escenas de lucha, ejecución de prisioneros) así como, principalmente, una serie de escenas íntimamente relacionadas con la posterior iconografía faraónica (la procesión de embarcaciones, el motivo del "Señor de los animales", la imagen de un personaje provisto de un flagelo y en actitud de carrera, y la escena en la que un personaje de mayor tamaño ejecuta con su maza a tres prisioneros arrodillados, en un acto análogo al ritual de la ejecución del

(1) Si bien en la producción reciente de los especialistas (Fattovich 1984: 51; Kemp 1992 [1989]: 46; Vercoutter 1992: 239; Maisels 1999: 60) el término proto-Estado (o protoreino) se ha vuelto corriente para referir a las unidades políticas del valle del Nilo anteriores a la unificación, no parece haber demasiado acuerdo ni rigor a la hora de definir el concepto. En nuestra apropiación, el término referirá aquí a situaciones sociohistóricas ya estatales, es decir, en las que puede suponerse la existencia del monopolio legítimo de la coerción como prerrogativa exclusiva de la élite. Hemos tratado esta cuestión en Campagno 2002b: 49-60. 


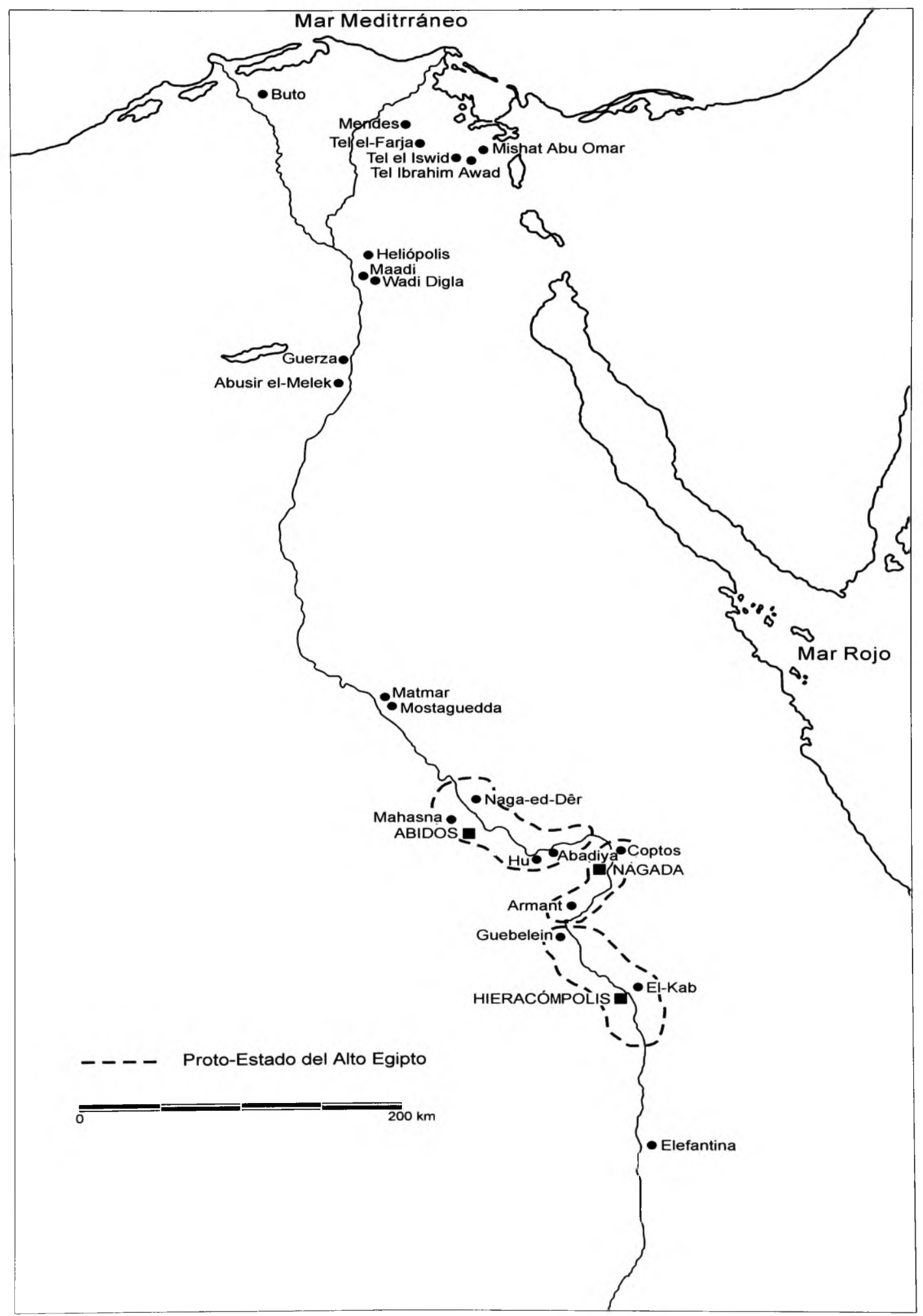


enemigo celebrado a lo largo de la época faraónica) (Cervelló 1996a: 202-203). Más allá de la Tumba 100 , otros enterramientos de comienzos de Nagada III - como la tumba $2(6,5 \mathrm{~m}$ de largo x $2,10 \mathrm{de}$ ancho y 4,15 de profundidad) o la Tumba 11 (5m de largo x 2,40 de ancho), ambas de la Localidad $6-$ testimonian la continuada construcción de tumbas de élite durante la época "proto-estatal" (Hoffman, Lupton y Adams 1982: 38-60; Adams 1996: 1-15).

Respecto de Nagada, entre las principales construcciones que remiten a Nagada II, sobresale un muro de 2m de espesor (Kemp 1977: 198; Bard 1994: 77) y los restos de un conjunto de "grandes casas palatinas para la residencia de la élite" (Hassan 1988: 156). Por otra parte, el hallazgo de ciertas impresiones de sellos sobre fragmentos de arcilla ha sugerido la posibilidad de algún tipo de actividades de índole administrativa (Fattovich 1984: 62; Barocas, Fattovich y Tosi 1989: 301). En cuanto a la evidencia funeraria, la utilización, en la fase Nagada II, de una nueva necrópolis (Cementerio T) con tumbas de mayores dimensiones y con ajuares funerarios más elaborados parece confirmar la existencia de una élite sensiblemente diferenciada del resto de la población (Kemp 1973: 39-43; Davis 1983: 17-28; Bard 1989: 240-244; 1994: 97-109). En particular, las tumbas T23, T25 y T20 (y posiblemente también la T15), cuya datación se extiende entre Nagada IIc-d y Nagada IIIa, presentan un aspecto rectangular con muros perimetrales y paredes interiores de adobe y con unas dimensiones superiores a los $5 \mathrm{~m}$ de largo $\mathrm{x} 2 \mathrm{~m}$ de ancho. Lo que resulta fundamentalmente relevante de estas tumbas es su estrecho paralelismo con el formato de la Tumba 100 de Hieracómpolis así como su similitud con algunas tumbas en el Cementerio U de Abidos: sobre la base de esas relaciones, $\operatorname{Kemp}(1973: 42)$ ha propuesto que "la Tumba 100 de Hieracómpolis y las tumbas relacionadas en el Cementerio $T$ de Nagada deberían ser reconocidas como los lugares de enterramiento de reyes predinásticos"

En lo que refiere a Abidos (o tal vez a Tinis ${ }^{2}$ ), a partir de mediados de la fase Nagada II, el

(2) Actualmente se desconoce el emplazamiento de la ciudad de Tinis, referida en relatos posteriores como el lugar de origen de los monarcas de las Dinastías I y II. De haber existido tal ciudad, Abidos habría sido la necrópolis de los monarcas tinitas. Habida cuenta de la ausencia actual de testimonios del centro tinita, preferimos mantener aquí la denominación "Abidos" para este núcleo proto-estatal al norte de Nagada.
Cementerio U - que ya era utilizado desde Nagada I - presenta, en forma casi simultánea respecto de la Tumba 100 de Hieracómpolis y de las tumbas T5 y T23 de Nagada, un conjunto de sepulturas rectangulares de considerables dimensiones (de hasta $5 \mathrm{~m}$ de largo, $2,50 \mathrm{~m}$ de ancho y $2,50 \mathrm{~m}$ de profundidad), con indicios de revestimientos de madera y de sarcófagos, y que parecen haber estado ricamente equipadas con objetos de marfil y vasos de cerámica y piedra (Dreyer 1992b: 294; Dreyer et al. 1990: 54-62; 1993: 24-56). Si bien las tumbas no presentan decoración en sus paredes, las representaciones de algunos objetos de marfil en la tumba U-127 (Nagada IId) testimonian una suerte de procesión de "portadores de dones" así como el conocido motivo del "desfile de animales". escenas ambas que remiten a los cánones de la iconografía propiamente estatal (Dreyer $\mathrm{et} \mathrm{al}$. 1993: Pl. 6). Por otra parte, la tumba U-210, también de Nagada IId (Hartung 1998: 200-202, 212), presenta una impronta de sello que reproduce el motivo de la diosa Hathor asociada a una dimensión astral, conocido por una paleta decorada de principios de Nagada II (Vandier 1952: 443; Midant-Reynes 1992: 183-184): tal representación podría implicar la existencia de algún vínculo entre la diosa y el individuo enterrado en esa tumba abidena.

Por lo demás, ya ingresando en la fase Nagada III, el Cementerio U presenta las sepulturas más grandes y complejas de la época para todo el valle del Nilo. Se trata de tumbas de una o múltiples cámaras revestidas de adobe, con restos de sarcófagos de madera y de gran cantidad de vasos locales e importados de Canaán. Entre todas ellas, sobresale notablemente la tumba U-j, de Nagada IIIa2 (Dreyer 1998). Por una parte, sus grandes dimensiones $(9,10 \mathrm{~m}$ de largo, $7,30 \mathrm{~m}$ de ancho y 1,55 de profundidad) la convierten en el sepulcro conocido más grande de su tiempo. Por otra parte, se destaca la presencia de un bastón de madera de las mismas características que el cetro heqa de los faraones. Pero además, aparece en la tumba un notorio conjunto de inscripciones realizadas sobre algunos vasos y tablillas de marfil que parecen aludir a la procedencia de los productos contenidos en esos vasos y que constituyen los primeros testimonios fehacientes de un sistema de escritura, es decir, de una práctica eminentemente estatal.

Por cierto, las diferencias cualitativas que pueden ser detectadas en sitios como Hieracómpolis, 
CAMPAGNO, M. Los "proto-Estados" del Alto Egipto y la unificación del valle del Nilo. Rev. do Museu de Arqueologia e Etnologia, São Paulo, 12: 123-141, 2002.

Nagada o Abidos a partir de mediados de Nagada II no constituyen la regla en el Alto Egipto sino más bien la excepción. En la mayor parte de los asentamientos conocidos se verifica una notable continuidad en el tipo de prácticas mortuorias ejecutadas por la comunidad, a veces con cierta tendencia a la expansión cuantitativa de los bienes constitutivos de algunos ajuares funerarios, lo cual puede indicar la existencia de una élite de jefatura, pero sin la aparición de patrones de enterramiento fuertemente divergentes. En algún asentamiento puntual, como sucede en Guebelein (Galassi 1955: 5-17; D'Amicone 1994: 19-28) - un sitio cercano a Hieracómpolis - , la aparición aislada de un tejido con una iconografía muy similar a la existente en la Tumba 100 de Hieracómpolis, pero en un contexto documental que no presenta ningún cambio drástico en materia de diferenciación social, probablemente deba atribuirse a la imposición de un patrón de dominio exterior (Cervelló, 1996b: 11). En efecto, la aparición de un tipo de iconografía presumiblemente estatal en un sitio que no ofrece indicios de una élite suficientemente poderosa y en el marco de los conflictos que desembocaron en el advenimiento del Estado egipcio puede ser interpretada como una imposición exterior, que tal vez sea indicio de la sumisión de Guebelein al núcleo estatal forjado en sus cercanías.

En otras localidades, como en lo que refiere a Mahasna - vecina a Abidos - incluso se verifica una sensible disminución del tamaño de las tumbas y la riqueza de sus ajuares funerarios con respecto a la época previa (Wilkinson 1996: 79-80, 85: Castillos 1997: 254). Una situación similar se registra en las necrópolis de la región de Abadiya-Hu (un área entre Abidos y Nagada), que incluyen algunas tumbas de considerable riqueza a finales de la fase Nagada I, y que presentan una merma en el volumen y la riqueza promedio de las tumbas a partir de la fase Nagada II (Castillos 1997: 254; Wilkinson 2000: 380-382). ${ }^{3}$ Del mismo modo, en Naga ed-Dêr, las tumbas del Cementerio N7000 presentan una moderada riqueza funeraria, a excepción de

(3) De hecho, Wilkinson (2000: 380-382) considera que Abadiya debió constituir durante fines de Nagada I un centro equivalente a los existentes en Hieracómpolis, Nagada y Abidos, que habría entrado en crisis a comienzos de Nagada II como consecuencia de la presión de los otros centros, especialmente Abidos, dada su mayor proximidad. algunas de ellas (como la 7304, cuyo ajuar más elaborado incluía bienes de procedencia asiática), que podrían haber pertenecido a jefes de la comunidad (Savage 1997: 226-268). Por su parte, en relación con Armant, Bard indica que "posiblemente, los entierros más ricos de Nagada IIc-d representan a individuos de mayor status en la sociedad aldeana" Sin embargo, "aunque la autoridad de algunos miembros de la sociedad aldeana probablemente se incrementó a través del tiempo, el poder político real no se desarrolló dentro de la unidad social de pequeña escala de la aldea" [...] Una sociedad de clases podría emerger en grandes centros como Nagada, no en pequeñas aldeas campesinas como Armant" (Bard 1994, 71, 70, 73. Cf. también Griswold 1992: 196; Wilkinson 1996: 81-82).

De este modo, la situación que parece haberse constituido en el Alto Egipto en el transcurso de la fase Nagada IIc-d es la de una pluralidad de sociedades de jefatura que habrían quedado subordinadas a tres núcleos, los cuales, habida cuenta de los testimonios disponibles, pueden ser considerados como "proto-estatales": Hieracómpolis, Nagada y Abidos. Ciertamente, no hay forma de establecer los pormenores de ese proceso. Por un lado, la extensión de cada uno de esos "proto-Estados" es simplemente conjetural: si aquí se ha sugerido que Guebelein pudo haber sido incorporado al ámbito de control hieracompolitano, o puede sugerirse que Armant pudo quedar bajo la órbita de Nagada, o que Abadiya y Naga edDêr pudieron someterse al dominio de Abidos, se trata de probabilidades sustentadas básicamente en la proximidad geográfica de cada una de esas comunidades a cada uno de los centros "proto-estatales". Por otro lado, no hay elementos que permitan elaborar la secuencia específica de sucesos: algunas comunidades podrían haber sido rápidamente englobadas bajo la potencia expansiva de aquellos núcleos; otras, en cambio, podrían haber preservado su autonomía por mayor tiempo. En todo caso, ya subordinadas o aún autónomas, está claro que esas comunidades no jugarían un papel protagónico en el proceso de unificación en curso. En el Alto Egipto, ese proceso comenzaría con tres participantes y culminaría con un único protagonista en escena. 
CAMPAGNO, M. Los "proto-Estados" del Alto Egipto y la unificación del valle del Nilo. Rev. do Museu de Arqueologia e Etnologia, São Paulo, 12: 123-141, 2002.

III.

¿De qué modo se llevó a cabo la unificación del Alto Egipto? ¿Qué tipo de relaciones entablaron entre sí esos tres centros? A juzgar por la continuidad de las escenas vinculables a la guerra que son descriptas iconográficamente, la aparición de estos núcleos estatales no disipó el clima de hostilidades en el que había emergido la práctica estatal. Y es posible suponer razones para ello: por un lado, si la principal razón de los conflictos era la disputa por los bienes de prestigio, en la medida en que siguiera existiendo más de una unidad sociopolítica - aun cuando ahora se tratara de unidades estatales -, la competencia por los bienes de prestigio podía continuar. Pero además, por otro lado, la existencia misma de los proto-Estados podía impulsar los conflictos bélicos, y esto por dos motivos. En primer lugar, porque el monopolio de la fuerza y la institución de un vínculo permanente de dominación ya habría sido probado con éxito como estrategia para eliminar la competencia de las comunidades rivales, de modo que podía constituir ahora un "modelo" de acción política hacia el exterior. Y en segundo lugar, porque la representación que el pensamiento egipcio había trazado acerca del Estado - y más precisamente, de su cúspide, el faraón - lo equiparaba a una entidad divina todopoderosa, uno de cuyos predicados básicos era el de una práctica siempre victoriosa de la guerra, que imponía el orden por sobre el caos (Campagno 1998a: 71-75; 1998b: 237-243). De esta manera, la extensión de la práctica estatal hacia nuevas latitudes podía ser entendida ahora como la afirmación del mandato divino, como la imposición del orden querido por los dioses en las tierras únicamente habitadas por las fuerzas del caos.

De hecho, dos de las escenas decoradas en la Tumba 100 de Hieracómpolis que hemos mencionado - la del Señor de los Animales y la del rey ejecutando a sus enemigos con la maza - atestiguan la temprana creencia en las cualidades del monarca como aquél que impone el orden divino. Por cierto, la expansión del Estado reafirmaría y multiplicaría la corriente de bienes de prestigio hacia la nueva élite estatal. Sin embargo, el objetivo básico de las guerras habría variado. Una vez que hubo de adquirir un lugar en el universo de lo pensable, la práctica estatal podría comenzar a ser percibida como una manifestación de la voluntad de los dioses y su extensión podría verse como el despliegue de esa voluntad divina. En este marco, si simultáneamente hubiera prevalecido en el Alto Egipto más de una organización social de tipo estatal como Hieracómpolis, Nagada y Abidos, con concepciones similares acerca del sentido de la práctica estatal, es muy posible que pronto entraran en conflicto. Es más, tratándose de sociedades estructuralmente similares, es posible también que se hubieran visualizado mutuamente como antagonistas.

Ahora bien, vayamos por partes. ¿Qué puede decirse de las relaciones trazadas entre Hieracómpolis y Nagada? En rigor, no existe evidencia directa para establecer de modo seguro los vínculos establecidos entre ambos centros hacia finales del período Predinástico. Sin embargo, existen dos tipos de indicios para asumir la imposición del Estado hieracompolitano sobre el nagadense. Por una parte, en un plano simbólico, se ha vinculado la temprana relación entre Hieracómpolis y Nagada a la posterior relación existente entre los dioses adorados en esos centros, respectivamente Horus y Seth (Kemp 1992 [1989]: 47-56; Baines 1991: 98-99; 1995: 100; Vercoutter 1994: 406). En efecto, dado que, en los relatos míticos, ambos dioses eran los eternos antagonistas, siendo Horus el eterno vencedor, y dado también que - salvo contadas excepciones - el faraón se identificó siempre con el dios-halcón y no con Seth - quien quedó asimilado a las fuerzas del caos -, se ha sugerido que ello podría indicar un predominio inicial de los seguidores de Horus sobre los adoradores de Seth (Baines 1991: 98). ${ }^{4}$

(4) En la misma línea inferencial, la concepción egipcia de su territorio en términos duales, esto es, el Alto Egipto y el Bajo Egipto - que posteriormente fue aplicada para distinguir el valle y el delta del Nilo -, pudo ser, en el inicio, una representación acuñada en Hieracómpolis para distinguir ambos núcleos antagónicos. En efecto, como señala Vercoutter (1992: 242), Alto y Bajo Egipto son términos relativos, y Nagada está en posición de Bajo Egipto para los habitantes de Hieracómpolis. Incluso más, el hecho de que. posteriormente, el Bajo Egipto histórico (el delta) fuera representado por una corona roja, un símbolo aparentemente originario de Nagada (Kemp 1992 [1989]: 56; Vercoutter 1992: 242-243; Baines 1995: 95-96), podría corresponder con una reformulación del concepto de norte establecida siempre desde el extremo sur. De hecho, Dreyer (1998: 88-89) ha sugerido la posible representación de las Dos Tierras (tauy) junto al símbolo del rey, en unos vasos en la tumba U-s de Abidos (Nagada IIIa-b). Si esto fuera así, se fortalecería la posibilidad de considerar el carácter relativo y no absoluto de las dos mitades que compondrían Egipto. 
Pero por otra parte, más allá de este tipo de inferencias, el registro arqueológico de Nagada presenta una notable novedad a partir de la fase Nagada III. Se trata de una fuerte reducción en la calidad de los ajuares funerarios, en las dimensiones e incluso en la cantidad de tumbas existentes en relación con los testimonios del período precedente. En efecto, "comparadas con las tumbas que datan de Nagada II, hay relativamente pocas tumbas de Nagada III en los Cementerios $N, B$ y $T$ [...] Las tumbas de Nagada III en Nagada muestran una caída colectiva en riqueza, y en el número promedio de vasijas y otros bienes por tumba, particularmente en el Cementerio T. Tal vez durante Nagada III el Cementerio T ya no representaba a la élite gobernante en Nagada" (Bard 1994: 108). La disminución en calidad y cantidad de testimonios funerarios y de asentamiento de la sociedad nagadense contrasta con la situación registrada en la misma época en Hieracómpolis: "La ciudad de Nején [= Hieracómpolis] continuaba el crecimiento y ostentaba grandes complejos de palacio y templo y una necrópolis real aislada en el desierto - todos elementos característicos de las posteriores capitales faraónicas" (Hoffman, Hamroush y Allen 1986: 184-185). En particular, el cementerio de la Localidad 6 es reutilizado durante Nagada III para volver a situar allí las tumbas de la élite local (Hoffman, Lupton y Adams 1982: 38-60; Adams 1995: 46-64).

Así, una posible crisis en Nagada podría ser explicada en términos de su subordinación al Estado hieracompolitano: es que, aun cuando pudiera persistir una élite local, el drenaje de bienes de prestigio que Hieracómpolis podría haber impuesto en materia de tributo o de monopolio de las redes de intercambio tendría que haber repercutido necesariamente de modo de producir una sensible merma de ese tipo de bienes en las tumbas de la capital del antiguo reino rival. De tal modo, en el transcurso de Nagada III, "las bases del poder se habían mudado hacia otras regiones - a Abidos, a Saqqara y a Hieracómpolis pero no [habían permanecido] en Nagada" (Bard 1994: 108). En efecto, la pérdida de autonomía de Nagada no habría implicado su aniquilación sino su incorporación a una entidad estatal mayor: en función de ello, su región podía continuar siendo escenario para la creación de nuevas construcciones monumentales. aunque éstas fueran decididas ahora desde centros exteriores al antiguo "protoEstado" local..$^{5}$

Ahora bien, ¿qué papel le cupo a Abidos en ese crítico pasaje entre las fases Nagada II y III, en el que aparentemente el Estado se consolidó en Hieracómpolis y entró en crisis en Nagada? Algunos autores tienden a pensar que los reyes de Hieracómpolis debieron continuar su expansión hacia el norte, de modo que, luego de la incorporación de Nagada, habrían conquistado la región de Abidos, estableciendo allí su nueva residencia (Vercoutter 1992: 244; Adams 1995: 24; Cervelló 1996b: 11; Menu 1996: 32). En esta línea, las grandes tumbas de Nagada III corresponderían a los recién llegados, en tanto que la continuación del crecimiento en población y complejidad del centro de Hieracómpolis atestiguaría que el proceso de conquista siguió la dirección sur-norte y no la contraria. Sin embargo, si bien es cierto que el dinamismo político de Hieracómpolis recién comenzaría a declinar a partir de su "provincialización" en el período Dinástico Temprano, no parece haber ningún indicio que permita postular un corte abrupto en Abidos, a comienzos de Nagada III, como consecuencia de la llegada de los hieracompolitanos. De hecho, el Cementerio U de Abidos sería utilizado de modo continuado a lo largo de las fases Nagada I-III y las variaciones que se registran allí en el estilo arquitectónico de los sepulcros no parecen haber dependido de criterios dictados desde el exterior.

Otros autores sostienen una posición opuesta, al señalar - sobre la base de los antecedentes preestatales del Cementerio U - que Abidos debió

(5) De hecho, la aparición posterior, hacia comienzos de la Dinastía I, de dos tumbas monumentales con superestructuras con reentrantes - similares a las edificadas en la necrópolis de Saqqara - ubicadas a más de $6 \mathrm{~km}$ de los antiguos cementerios nagadenses podría ser atribuible a algún tipo de "alianza de postunificación entre Nagada y los poderes ahora establecidos en el norte [en el área menfita]" (Bard 1994: 109). La política constructora de! Estado del Alto Egipto en la región de Nagada también parece haber dejado su huella en Coptos, una localidad que - por su cercanía a Nagada - debió formar parte del anterior proto-Estado local. En efecto, es muy posible que durante Nagada IIIa se edificara en Coptos un gran recinto ceremonial en el cual estarían emplazadas tres estatuas colosales del dios Min, de más de $4 \mathrm{~m}$ de altura y 2 toneladas de peso cada una, así como otras tres estatuas representando leones, de aproximadamente 1.5 m de largo (Williams 1988: 35-59; Kemp 1992 [1989]: 102-107; Adams y Cialowicz 1997: 46-48). 
ser el centro estatal que se impondría en el sur, antes o incluso después de la expansión hacia el norte. En tal sentido han sido interpretados los grabados recientemente hallados en Dyebel Chauti, los cuales parecen registrar "la conquista abidena de la región de Nagada en el inicio de la historia faraónica" (Darnell y Darnell 2000). ${ }^{6}$ Con respecto a la posición del reino de Hieracómpolis, ésta podría haber sido la de "un centro separado que se integró al núcleo de Abidos" (Baines 1995: 103), dado que "fueron los gobernantes de Tinis quienes finalmente triunfaron en la lucha por el poder político sobre todo el país" (Wilkinson 1996: 7). ${ }^{7}$ Ahora bien, si el papel de Abidos en la crisis de Nagada efectivamente podría haber sido mayor del que solía suponerse, la hipótesis de un predominio directo - e incluso violento - de Abidos sobre Hieracómpolis no cuadra bien con los datos disponibles. En efecto, por un lado, un predominio a comienzos de Nagada III no podría dar cuenta del continuado uso del cementerio de la Localidad 6 de Hieracómpolis, con tumbas de grandes dimensiones (Tumba 1: 6,50 x 3,50m), paredes de adobe y paneles de madera, que son contemporáneas (Nagada IIIb) de los enterramientos en el Cementerio U de Abidos (Hoffman, Lupton y Adams 1992: 38-60; Adams 1996: 1-15). Por el otro lado, un triunfo militar de Abidos sobre Hieracómpolis en la época del paso de la Dinastía 0 a la I no podría explicar fácilmente las razones de la especial veneración que los reyes Escorpión y Nármer parecen haber rendido a los santuarios hieracompolitanos. $^{8}$

(6) Cf. también Darnell 2002: 10-19. La escena de Dyebel Chauti incluye un personaje identificado como Horus Escorpión, un hombre armado que conduce a un prisionero atado con una soga y el motivo del buitre capturando una serpiente, que es usualmente interpretado como un símbolo de victoria. En conjunto, se trata de una de las evidencias más tempranas que permiten advertir la existencia de conflictos de índole militar en el Alto Egipto. en una época anterior a la unificación política de la región. (7) Algo similar propone Cialowicz (2001: 210-211), aunque con algún predominio transitorio de Hieracómpolis, en tiempos del rey Escorpión.

(8) Recientemente, Wilkinson (2000: 392-293) ha sugerido que sería el propio Nármer, en tanto rey de Abidos, el encargado de triunfar sobre Hieracómpolis, incorporando este proto-Estado a sus dominios. Sin embargo, la conocida cabeza de maza de Escorpión, hallada como ex voto en Hieracómpolis, implica que ya este monarca, predecesor
De hecho, si bien la hipótesis de la expansión conquistadora de uno u otro proto-Estado no puede ser descartada completamente, quizá fuera más probable que, durante los conflictos entre Hieracómpolis y Nagada, Abidos hubiera participado a favor del primero y en contra de sus vecinos. De hecho, el Dyebel Chauti-donde se encuentran las inscripciones de victoria, asociadas con Abidos - se halla en medio de un camino terrestre que podría permitir la comunicación entre Hieracómpolis y Abidos sin pasar por la intermedia Nagada. Así pues, también es posible pensar en la probabilidad de una alianza más o menos pacífica entre las élites de Hieracómpolis y Abidos, constituyente de la nueva élite de un único "proto-Estado" extendido por el Alto Egipto. ${ }^{9}$ Una hipótesis tal podría resultar más verosímil a la hora de explicar la continuada importancia del centro del sur y, al mismo tiempo, en consonancia con la prosecución de la expansión hacia el norte, el traslado del centro de gravedad político y funerario hacia Abidos, sin involucrar la necesidad de una conquista en regla del área abidena ni del área hieracompolitana, para las cuales no existe ninguna evidencia disponible.

En cualquier caso, hacia comienzos de la fase Nagada III (3200 a.C), el Alto Egipto ya ofrece indicios que permiten suponer que se hallaba políticamente unificadobajo una mismaélite estatal. En efecto, la práctica estatal ya se habría extendido lo suficiente como para articular un considerable conjunto de comunidades en una misma red de prácticas. Ahora bien, para tal época, el efecto de las prácticas estatales ya se dejaba sentir en horizontes considerablemente más lejanos que aquellos del Alto Egipto.

de Nármer, podría haber desplegado cierta actividad ritual en el centro sureño. Por lo demás, si la unificación hubiera sido tan tardía y como efecto de una "victoria tinita". resulta llamativa la total ausencia de resistencias políticas o divergencias socioculturales en Hieracómpolis durante el período Dinástico Temprano, máxime si se considera que, con el traslado de la élite estatal a Menfis, la lejanía de Hieracómpolis respecto del principal centro estatal abría las puertas a la posibilidad de una fisión exitosa. (9) La hipótesis de una alianza entre Hieracómpolis y Abidos también ha sido recientemente sostenida por Savage (2001: 133-134), aunque el autor la sitúa en una época sensiblemente posterior, en el inicio de la Dinastía I Cf. también Gundlach (1998: 62), quien propone que sólo el cementerio real habría sido trasladado a Abidos, en tanto el templo y la residencia real se habrían mantenido en Hieracómpolis. 
IV.

Ciertamente, la constitución de un Estado en toda el área correspondiente al Alto Egipto no sólo desencadenaría una serie de profundas variaciones en el modo en que se configuraban las sociedades en aquella región. Desde la época misma de la emergencia de las primeras prácticas de tipo estatal, las regiones periféricas también conocerían sus efectos. Durante la propia época que transcurre entre la emergencia de las primeras prácticas estatales y la unificación del sur (Nagada IIc-d), se produciría una expansión hacia regiones no controladas por el Estado emergente de ciertos elementos culturales del Alto Egipto - en especial, tipos de cerámica y prácticas funerarias - que, aun cuando no parecen implicar un dominio estatal efectivo en esas regiones, testimonian toda una serie de cambios.

En efecto, a poco de producida la aparición del Estado en el Alto Egipto, el registro arqueológico permite advertir una característica notable. Se trata de la constitución (o tal vez de la consolidación) de un conjunto de sitios alejados del área protoestatal y, sin embargo, con características culturales definidamente similares a las existentes en el Alto Egipto. Hacia el sur, a tal época es posible remontar los primeros elementos seguros de la existencia del asentamiento de Elefantina, distante a unos 100 km de Hieracómpolis - el núcleo "proto-estatal" más meridional. En efecto, los elementos más antiguos del santuario de Satet parecen corresponder a esta fase. Por otra parte, de acuerdo con Seidlmayer (1996: 111), la cerámica recobrada "aunque muestra algunas mezclas con la tradición del Grupo A, es principalmente de tipo egipcio". De tal modo, tanto la fundación del santuario como el predominio de la cerámica altoegipcia permiten advertir la proyección de características culturales allende los límites del territorio abarcado por la emergente sociedad estatal. Por lo demás, la presencia de cerámica nubia testimonia que Elefantina debió constituir un importante punto de contacto entre la expansiva cultura del Alto Egipto y la propia del Grupo A Temprano de la Baja Nubia.

Por cierto, la proyección de características culturales se haría mucho más ostensible, durante la misma época, hacia el norte. Desde Nagada IIc-d, en la zona norte del Egipto Medio o región del Fayum (a más de $400 \mathrm{~km}$ de Abidos) aparecen nuevos asentamientos cuyas prácticas mortuorias y cultura material en general remiten básicamente a las prácticas conocidas en el Alto Egipto. Tal es el caso de las necrópolis de Guerza y de Abusir elMelek, en donde los ajuares funerarios presentan características típicamente sureñas (Vandier 1952: 436-466; Seeher 1992: 231-232; Bard 1994: 1718; Adams y Cialowicz 1997: 18-19). Al mismo tiempo, otros sitios contemporáneos de la región presentan mayor heterogeneidad: tanto en Haraga como en Sedment coexisten tipos cerámicos procedentes tanto de la tradición cultural altoegipcia como de la maadiense, originaria del norte (Williams 1982: 13-21; Bard 1994: 18). En tal sentido, Bard (1994: 18) concluye que "es probable que la región del Fayum fuera el lugar donde las dos culturas predinásticas del Alto y del Bajo Egipto entraran en contacto directo por primera vez"

Durante el mismo período, la presencia de sitios con características meridionales en el norte llegaría aún más lejos, hasta el vértice nor-oriental del delta del Nilo. En efecto, a más de $600 \mathrm{~km}$ de los núcleos sureños, el sitio de Minshat Abu Omar cuenta con un gran cementerio cuyas tumbas más tempranas se remontan a Nagada IIc-d 1 (Kroeper 1986-87: 73-94). Tales sepulcros contenían restos cerámicos que pertenecen "casi totalmente a la tradición del Alto Egipto" (Wilkinson 1996: 5). Por su parte, la aparición de cerámica procedente de Palestina constituye un testimonio claro de los contactos establecidos con la región cananea (Kroeper 1988: $11-19$; Wilkinson 1996, 5). Así pues, al mismo tiempo que Elefantina parece constituir un sitio de contacto entre la región "proto-estatal" del Alto Egipto y las comunidades nubias, Minshat Abu Omar parece presentarse como el principal punto de contacto entre la cultura altoegipcia y Palestina. ${ }^{10} \mathrm{~A}$ diferencia de lo sucedido en el sur, sin embargo, la extensión hacia el norte de la cultura material del área en la que estaba emergiendo el

(10) De hecho, los primeros testimonios de otros asentamientos entre el valle del Nilo y Minshat Abu Omar, en torno de los brazos Tanítico y Pelusíaco del Nilo - Beni Amir, Kafr Hassan Daud, probablemente Ezbet el-Tell (Kufur Nigm) - también se remontan a la fase Nagada IIc (cf. Mortensen 1991: 33; Abd el-Moneim 1996: 253-273; Lovell 1997: 34-41: Hassan 2000: 37-39). Es probable que tales sitios hayan constituido escalas en la ruta que conectaba el Alto Egipto con Palestina. 
CAMPAGNO, M. Los "proto-Estados" del Alto Egipto y la unificación del valle del Nilo. Rev. do Museu de Arqueologia e Etnologia, São Paulo, 12: 123-141, 2002.

Estado alcanzaría regiones situadas a varios centenares de kilómetros de los focos estatales iniciales.

Ahora bien, los efectos de la expansión de la cultura material altoegipcia hacia el norte no se evidencian solamente por la existencia de asentamientos con todas las características típicas de la cultura del Alto Egipto. A partir de tal expansión, todos los sitios pre-existentes del Bajo Egipto ingresan en un período de sensibles transformaciones. Por un lado, para entonces se registra la desaparición de Maadi, un asentamiento que había entablado intercambios con el Alto Egipto tanto como con Palestina y que constituye el sitio septentrional más importante de cuantos se conocen en el período previo (Rizkana y Seeher 1987: 78-80; 1990: 104). La estratigrafía de otros sitios del delta, tales como Tel el-Farja (Chlodnicki et al. 1992: 171-190; Chlodnicki y Cialowicz 2000: 59-76) y Tel el-Iswid sud (van den Brink 1989: 54-108), en cambio, presenta una notable discontinuidad indicada por un salto que separa los estratos inferiores (Nagada IIc) - con una fuerte preponderancia de cerámica de la tradición del Bajo Egipto - de los superiores (Nagada III) - con claro predominio de cerámica de estilo sureño. Finalmente, otros sitios del delta - entre los que se destacan Buto (Köhler 1992: 11-22; von der Way 1992: 1-10), Tel Ibrahim Awad (van den Brink 1992: 43-68; Eigner 2000: 30-35) y Mendes (Brewer y Wenke 1992: 191-197; Friedman 1992: 199-205) - registran también la aparición de elementos de la cultura material altoegipcia aunque, a diferencia de los asentamientos anteriormente referidos, presentan una estratigrafía que evidencia continuidad en la ocupación de los sitios, con una intrusión gradual de la cerámica meridional. Tales situaciones podrían indicar que - en tales sitios - la adopción de la cultura procedente del Alto Egipto se habría dado en forma paulatina, sin la necesidad de alguna forma de ruptura, como la que parece evidente en los sitios que son abandonados transitoria o definitivamente o aun en aquellos que son establecidos inicialmente en esta época.

¿Por qué se produce, pues, toda esta serie de efectos? Hay algo que no debe escapar a nuestra consideración: si el contexto en el que surge el Estado egipcio estaba caracterizado por la existencia de unos conflictos intercomunitarios ligados a la competencia por los bienes de prestigio proceden- tes del exterior, la emergencia inicial de núcleos estatales en el Alto Egipto potenciaría aún más la demanda de bienes suntuarios para los miembros de esas élites devenidas estatales. En efecto, las prácticas de intercambio con Nubia, Palestina e incluso con la distante Mesopotamia se hallan bien documentadas para la época en que emerge y se consolida la práctica estatal en el valle del Nilo (Nordström 1972: 25-29; Andelkovic 1995; Mark 1998; Campagno 2002a: Caps. 5 y 7, con bibliografía).

Por cierto, la nueva condición estatal de las élites induciría una fuerte reconfiguración de los modos de obtención de esos bienes de prestigio. Por una parte, una élite estatal estaría en condiciones de multiplicar la demanda de productos de lujo procedentes del exterior. En efecto, provista con el monopolio de la coerción, esa élite disponía ahora de los excedentes extraídos de las comunidades dominadas en concepto de tributo, una parte de los cuales podía ser destinado a los intercambios con lejanas regiones. Por la misma razón, esa élite podía disponer de un artesanado a su servicio exclusivo, el cual podía expandir la producción local de objetos de prestigio, lo que requería de mayores cantidades de materias primas importadas. Pero, además, la demanda estatal tenía que ser cualitativamente diferente de la existente en épocas anteriores, habida cuenta de que, en la nueva situación, se orientaba a satisfacer los requerimientos que provenían no ya de una élite vinculada a su comunidad por lazos de parentesco sino del entorno de un líder ligado directamente a la condición de divinidad. En la nueva situación, la disponibilidad de unos excedentes obtenidos sistemáticamente y la ausencia de límites provenientes de las normas del parentesco para su consumo hacían posible que el Estado pudiera continuar demandando bienes de prestigio, pero en una magnitud desconocida con anterioridad.

Por otra parte, la nueva capacidad operativa de la sociedad estatal podría estar en correlación con la posibilidad de emprender políticas más agresivas para la obtención de tales bienes, mediante algún tipo de ataque a regiones lejanas o estableciendo sitios dependientes en áreas estratégicas para la obtención de los bienes provenientes del exterior. Ciertamente, la existencia de acciones de saqueo dirigidas desde el Alto Egipto hacia las regiones periféricas no dispone de evidencia para esta época; permanece, sin embargo, como una 
posibilidad verosímil, ${ }^{11}$ habida cuenta de las actividades dirigidas por el Estado en la siguiente fase. En cambio, la presencia de sitios directamente relacionados con las prácticas culturales altoegipcias se halla claramente documentada, como hemos visto, tanto hacia el sur como hacia el norte. En este sentido, el emplazamiento o la reutilización de asentamientos tales como Elefantina - en un área vinculada directamente a la cultura nubia del Grupo A - y Minshat Abu Omar - en la ruta que conectaba el Nilo con Palestina - parecen testimoniar una política deliberada de las élites altoegipcias por obtener los bienes procedentes de las regiones exteriores. La intensificación de tal política en la fase siguiente, con el probable establecimiento de grupos egipcios en Palestina (Gophna 1990: 1-11; Brandl 1992: 445; Levy et al. 1997: 14-16), parece confirmar tal asunción de los intercambios con regiones lejanas como práctica específicamente estatal.

En el delta, especialmente, esa actividad estatal parece haber inducido una serie de notables efectos. Por un lado, la crisis final de Maadi - un asentamiento que debió jugar un papel clave hasta entonces en la intermediación de los productos asiáticos con dirección al alto valle - podría haber sido consecuencia de la nueva estrategia de abastecimiento directo de los productos cananeos iniciada por el Alto Egipto. Ciertamente, la canalización de los intercambios con Palestina a través de Minshat Abu Omar bien podría haber inducido la finalización de los contactos entre el Alto Egipto y Maadi. Resulta más difícil de establecer, en cambio, si fue la pérdida del dinamismo "comercial" de Maadi la que condujo a su despoblamiento o si el Estado altoegipcio decidió eliminar por la fuerza la presencia de un asentamiento que podía interferir en sus conexiones con el Asia. En sitios tales como Tel el-Farja o Tel el-Iswid (sud), la existencia de un aparente período de

(11) Por ejemplo, no es posible descartar la posibilidad de que la desaparición de Maadi guarde relación con alguna situación de conflicto con el Estado del alto valle. En efecto, como indica Tutundzic (1993: 54), "la notoria pérdida de contacto entre la cultura maadiense y guerzeense al comienzo del período Guerzeense Tardio [esto es, Nagada IIc-d] podría haber sido consecuencia del comienzo de una enemistad guerzeense hacia los habitantes de Maadi y sus alrededores, no simplemente la terminación de su existencia". En un sentido similar, cf. Bard 1994: 27: Wilkinson 1996: 95-96. despoblamiento entre la época de prevalencia de la tradición local y la de predominio de la cultura meridional parece sugerir que la llegada del Estado al delta introdujo algún tipo de cambios drásticos, cuya índole estricta se nos escapa.

En otros sitios preexistentes del delta, en cambio, la creciente presencia de objetos estilísticamente originarios del valle en coexistencia con los producidos bajo criterios locales parece indicar un tipo de contactos más bien pacíficos. En particular, las relaciones con Buto (en donde - al calor del contacto con el expansivo Alto Egipto - serían adoptadas las técnicas de producción artesanal del sur) podrían ser interpretadas en relación con la importancia de ese asentamiento en los contactos con el corredor siriopalestino via maris (Faltings 1998) y - quizá de cierto temprano renombre en materia de cultos, tal como sucedería en tiempos posteriores (Redford 1983: 69-77). En esas condiciones, a diferencia de la estrategia seguida en relación con Maadi, el Alto Egipto podría haber buscado intensificar sus vínculos con Buto, un proceso que culminaría en el siguiente período, con la incorporación del asentamiento al territorio controlado directamente por el Estado surgido en el sur.

V.

Ahora bien, si el final de la fase Nagada II implica no sólo la época de la confluencia de los proto-Estados iniciales en un único proto-Estado en el Alto Egipto sino también la expansión supraregional de la cultura proto-estatal, la época subsiguiente, Nagada IIIa-b (3200-3000 a.C.), sería la de la culminación del proceso de homogeneización cultural y política del valle y el delta del Nilo. Hacia el sur, el área de Elefantina quedaría crecientemente incorporada a la órbita del Estado altoegipcio. De hecho, la existencia allí de una fortaleza egipcia desde la que serían lanzadas las campañas de ataque a Nubia se remonta al 3000 a.C. (Seidlmayer 1996: 112) e implica que, al menos desde entonces, la región formaba parte del territorio controlado por el Estado egipcio.

Hacia el norte, también se experimentan notorios cambios a partir de la fase Nagada III. En Matmar, uno de los principales asentamientos de tiempos de Nagada II en tal región, las tumbas de Nagada III presentan una importante reducción de bienes de prestigio y símbolos de autoridad en 
relación con el período precedente. De acuerdo con Wilkinson (1996: 75), "esta declinación puede estar asociada con las etapas finales de la formación del Estado, un proceso centrado principalmente en el Alto Egipto y el área menfita, y en el cual las comunidades del Egipto Medio parecen haber jugado un papel muy pequeño". A pesar de ello, las tumbas de la cercana localidad de Mostaguedda alcanzan durante Nagada III sus mayores dimensiones y niveles de riqueza de sus ajuares (Wilkinson 1996: 77), lo cual podría indicar una mayor diversidad de dinámicas en la región en la época en que estaba siendo incorporada directamente a la órbita expansiva del Alto Egipto.

Por lo demás, la porción septentrional del Medio Egipto, que conoce la llegada de la influencia de la cultura del Alto Egipto durante Nagada IIc-d, presenta ahora características plenamente compatibles con la cultura meridional, tales como las ya evidentes en los ajuares y las normas funerarias generales del cementerio de Abusir elMelek. Algo similar puede indicarse para los sitios de Tarján, Heluán, Tura y Abu Rawash, situados un poco más al norte y cuyas necrópolis - utilizadas a partir de distintos momentos de Nagada III presentan prácticas mortuorias claramente asociables con las existentes en el Alto Egipto en el período precedente (Mortensen 1991: 30-36; Ellis 1992: 241-258; Bard 1994: 21; Wilkinson 1996: 38-47, 64-74; Köhler 1999: 49-56). De singular importancia, los cementerios de los cinco sitios han proporcionado cerámicas con los serejs e inscripciones de un conjunto de hipotéticos reyes predinásticos $-\mathrm{Ny}$ Hor, Hat-Hor, Cocodrilo, Ny-Neith y una serie de serejs anónimos o de lectura difícil (Kaiser y Dreyer 1982: 264-268; Dreyer 1992a: 259-263; van den Brink 1996: 140-158; Hendrickx 2001: 90-95; Köhler y van den Brink 2002: 59-81), ${ }^{12}$ así como de Iry-Hor, Ka y Nármer, en la época del

(12) Es probable que estos monarcas - o algunos de ellos - hayan reinado sólo regionalmente, de modo simultáneo a los reyes del Alto Egipto (cf. Dreyer 1992a: 259-263; 1998: 179; Wilkinson 1999: 53; 2000: 390-392). Si tal fuera el caso, se trataría de gobernantes locales que, al calor de la meridionalización cultural del norte, habrían adquirido los mismos símbolos utilizados en el sur para la expresión iconográfica de la realeza. Por lo demás, las inscripciones con los nombres de Iry-Hor, Ka y Nármer son indicio de que, al menos hacia fines de la fase Nagada IIIb, la región se hallaba políticamente unida al Estado de procedencia sureña. pasaje de la Dinastía 0 a la I. Por lo demás, en el inicio de la Dinastía I, la fundación de Menfis en el punto de unión del delta y el valle, tal como es referida por posteriores anales y por el comienzo de la utilización del cementerio real de Saqqara, también remite directamente a la consolidación de la fuerza expansiva del Alto Egipto en los territorios del norte.

En el delta, desde los inicios mismos de Nagada III, los sitios que anteriormente exhibían los rasgos característicos de la cultura local, presentan ahora un tipo de cultura material plenamente compatible con la del Alto Egipto. En relación con Buto, sería la culminación del proceso que von der Way (1992: 4) ha denominado "asimilación cultural por superposición". A partir de Nagada IIIa, no sólo se registran tipos cerámicos y líticos producidos al estilo de la tradición sureña (Köhler 1992: 13-22; Schmidt 1992: 34-37) sino también un tipo de instalaciones probablemente utilizadas para la preparación de cerveza, similares a las conocidas en el Alto Egipto y, ya hacia fines de Nagada IIIlb, un recinto en probable conexión con la adoración de un toro sagrado, que podría indicar la importancia de Buto en el ámbito ideológico del reciente Estado unificado (von der Way 1992: 6-7). En Tel Ibrahim Awad también se han hallado los muros de adobe de un posible santuario, datable a comienzos del período, en asociación con jarras de almacenamiento con la impronta de serejs con el "Halcón Doble", así como con los nombres de Ka y Nármer, lo cual atestigua la existencia de actividades productivas directamente ligadas al Estado (van den Brink 1992: 52-53; Eigner 2000: 30-35). Por su parte, la presencia, a partir de comienzos de Nagada III, de estructuras de adobe e industrias cerámica y lítica definidamente altoegipcias también se verifica en otros sitios del delta tales como Tel el-Farja (Chlodnicki et al. 1992: 171-190), Tel el-Iswid sud (van den Brink 1989: 55-108) y Mendes (Brewer y Wenke 1992: 191-197; Friedman 1992: 199-205), que implican "una completa meridionalización" de la cultura del Bajo Egipto (Chlodnicki et al. 1992: 183).

Por último, hacia el noreste, las tumbas de la tercera época de Nagada en el cementerio de Minshat Abu Omar ponen de relieve un salto en complejidad en relación con las del período anterior. En efecto, a la variación en las normas de colocación de los cadáveres en las tumbas, se agrega también la presencia de sepulcros con sarcófagos de madera y ajuares funerarios provistos con más de diez objetos 
(incluyendo artículos de cobre e importaciones de Palestina y Nubia), todo lo cual permite suponer la existencia de una considerable diferenciación social (Kroeper 1988: 11-19; 1992: 127-150). La presencia de una élite en Minshat Abu Omar durante Nagada III debe ser advertida en correlación con la aparición de un conjunto de vasos cerámicos con diversos serejs, lo cual pone de relieve la importancia de las actividades estatales desplegadas en el asentamiento, en una muy probable conexión con la posición de Minshat Abu Omar de cara a la ruta terrestre que unía el delta con la región de Palestina. ${ }^{13}$

Ahora bien, los principales elementos que - a propósito de los efectos generados por el Estado emergente - distinguen la época de Nagada IIIa-b en relación con el período precedente se vinculan a la índole estatal de un amplio conjunto de testimonios. En especial, resulta de notable importancia la aparición de serejs de diversos reyes tanto en el sur como en el norte, toda vez que se trata de un símbolo estrechamente asociado al monarca. Por cierto, no es necesario suponer que el control político del Estado se extendiera desde el principio y de modo homogéneo a lo largo de todo el valle y el delta. De hecho, la propia extensión de la cultura del Alto Egipto hacia el norte en la fase previa podría haber incidido en la aparición de otros efímeros proto-Estados en el norte, ${ }^{14}$ antes de que el Estado altoegipcio concluyera su expansión

(13) Por lo demás, a partir de Nagada III, existe evidencia procedente de otros asentamientos en el delta oriental o en sus cercanías que también presentan recipientes con serejs reales: el del "Halcón Doble" en El-Beda (van den Brink 1996: 143), el de Nármer en Ezbet el-Tell (Bakr 1988: 50-51) y los de Ka y Nármer en Kafr Hassan Daud (Adams y Cialowicz 1997: 22: Hassan 2000: 39). A ellos aún hay que agregar el serej de un rey no identificado (cuyo nombre, escrito con tres mazas, también ha sido detectado en Tura), inciso en una jarra procedente de algún sitio indeterminado del delta oriental (Fischer 1963: 44; van den Brink 1996: 145). (14) Si tal fuera el caso, se trataría de proto-Estados secundarios, en el sentido de que, a diferencia de los proto-Estados primarios surgidos en el Alto Egipto, aparecerían en un contexto en el que las representaciones simbólicas acerca del Estado podían hallarse disponibles con antelación a la materialización de las prácticas de tipo estatal. Similar consideración podría extenderse a la situación en la Baja Nubia en tiempos de Nagada IIIa. donde también parece emerger un proto-Estado, centrado en Qustul. Acerca de este proto-Estado, cf. Williams 1986: 163-190: O'Connor 1993: 20-23. Acerca de la distinción entre Estados primarios y secundarios, cf. Fried 1978: 37. política. Tal vez pudiera explicarse de este modo el hecho de que varios serejs (los del "Halcón Doble", Ny-Hor, Hat-Hor, Cocodrilo, Ny-Neith, el serej de las tres mazas) sólo aparecen en el norte. En todo caso, a juzgar por la situación existente durante la Dinastía I, es razonable pensar que los territorios comprendidos entre la primera catarata del Nilo (en las cercanías de Elefantina) y el mar Mediterráneo ya se hallarían políticamente unificados por el Estado durante la época en que finaliza la Dinastía 0 y comienza la Dinastía I, es decir, en tiempos de Ka y Nármer, reyes cuya presencia se documenta tanto en el valle como en el delta del Nilo.

Así pues, algo antes del 3000 a.C, la integración política de todo el territorio comprendido entre la primera catarata y el delta del Nilo habría quedado concluida. ¿Por qué el Estado del Alto Egipto habría llevado a cabo semejante política expansiva hacia el sur y el norte? Dos elementos deben ser tomados en consideración. Por un lado, nosotros habíamos señalado que la emergencia de la práctica estatal en el Alto Egipto durante Nagada IIc pudo haber sucedido en más de un centro. Ciertamente, el marco de conflictos en el que parecen emerger Hieracómpolis, Nagada y Abidos no debió haberse disuelto sino más bien potenciado, al trasladar la escala de las luchas intercomunitarias a un nivel interestatal. Ahora bien, con la conformación de un proto-Estado global en el Alto Egipto - hacia comienzos de Nagada III - podría haberse alcanzado cierta estabilización política del área, lo cual permitiría dirigir la fuerza político-militar de ese Estado hacia otras regiones. Se trata de una condición de posibilidad: en la medida en que los conflictos se produjeran en el interior del espacio altoegipcio, una expansión hacia otras áreas tenía que ser inviable. Pero en el momento en el que se hubiera consolidado un único Estado, la expansión era una posibilidad, máxime tomando en cuenta la nueva potencia bélica y de gestión de ese Estado en relación con las sociedades de su periferia.

Aquí es necesario volver a considerar un segundo elemento: la propia concepción egipcia - en proceso de definitiva plasmación - del faraón como rey-dios, garante de maat y enemigo del caos, que ejerce sus cualidades de guerrero en pos de afianzar el orden cósmico, en consonancia con el plan trazado por las divinidades. En la fase anterior - como hemos visto - tal concepción pudo ser una de las razones básicas 
para la unificación política del Alto Egipto. Ahora bien, al mismo tiempo que el Alto Egipto era unificado políticamente, regiones mucho más vastas habían empezado a cobrar una nueva homogeneidad cultural. A partir de la percepción egipcia del mundo - a la vez política y cósmica -, todas esas regiones podrían haber sido vislumbradas ahora como territorios pasibles de ser incorporados a la órbita del orden faraónico. Así, la homogeneidad cultural podría haber dado paso a la idea de unidad (Baines 1995: 102). Y, habida cuenta del sentido divino que la práctica estatal adquirió en el Nilo, la expansión política del Estado del Alto Egipto hacia todos los espacios considerados de algún modo como "egipcios" implicaba la extensión del cosmos, del orden querido por los dioses, sobre las regiones sumergidas en el caos. La unidad política de todo el territorio entre la primera catarata y el mar Mediterráneo - ya culturalmente homogéneo podía ser visualizada, entonces, como la continuidad del mandato divino, prescripto ya en los tiempos de las luchas en el corazón del Alto Egipto.

De este modo, y sin que decayeran las demandas de bienes suntuarios provenientes del exterior, el Estado podría haberse abocado a la conquista del territorio nilótico. Ese proceso de incorporación territorial parece haber tenido un sesgo ligado a la violencia (como parece inferirse de los testimonios de murallas, armas, o de cierta iconografía ${ }^{15}$ ), aun cuando no existe evidencia directa de conflictos. En todo caso, es posible que muchos de los centros que se sumaban ahora a ese Estado en expansión, lo hicieran sin necesidad

(15) La iconografía de Nagada III ofrece una gran cantidad de motivos asociados a la existencia de conflictos. Entre ellos, sobresalen las escenas que representan combates (mango de cuchillo de Dyebel el-Arak, paletas de los Toros y de los Buitres), poblados amurallados (paletas de las Ciudades y de Nármer) y ejecución de prisioneros (sello de Hieracómpolis, cabezas de maza real y de Escorpión, paleta de Nármer). Una lectura en clave historicista de tales documentos - tal como se hacía hasta hace poco tiempo - parece, sin embargo, muy poco apropiada, habida cuenta de las concepciones míticas a partir de las cuales debieron ser producidas todas esas escenas. Para un análisis de estos documentos, cf. Vandier 1952: 533-539, 584-599; Finkenstaedt 1984: 107-1 10; Monnet-Saleh 1986: 227-238; 1990: 259-266; Midant-Reynes 1992: 223-229; Vercoutter 1992: 178-199; Menu 1996: 35-48. de ser conquistados por la vía militar. En efecto, la sumisión más o menos voluntaria a semejante manifestación de fuerza nunca antes vista podría haber jugado un papel incluso más importante que el desempeñado efectivamente por el ejercicio directo de la violencia. ${ }^{16}$ Aún más, en la medida en que la concepción divina del rey fuera admitida en las regiones que el Estado iba incorporando - y la potencia bélica y de gestión estatal podían constituir un sólido soporte material para semejante concepción - , la probabilidad de resistencia a la expansión se tornaría remota. En efecto, más que como la imposición arbitraria de un invasor, la llegada del Estado sureño podría haber sido vista como el despliegue de un plan que los propios dioses habían decidido para Egipto.

\section{VI.}

En el umbral del III milenio a.C., con el inicio de la Dinastía I, el formidable impulso expansivo de la práctica estatal surgida en el valle del Nilo comenzaba a cesar. Atrás quedaba un período de tres o cuatro siglos de aceleradas transformaciones sociales, que se había iniciado con la aparición de los primeros núcleos proto-estatales en el Alto Egipto y había concluido con la unificación política de todo el territorio comprendido entre la primera catarata del Nilo y el mar Mediterráneo. A partir de allí, comenzaría una etapa cuyo principal signo sería el de la consolidación del tipo de sociedad estatal forjada por entonces. Se trataba de una configuración social que se revelaría profundamente duradera, como lo demostraría el paso de los siguientes milenios.

(16) Por ejemplo, Hoffman (1979: 322) indica que el matrimonio entre Neithotep y el rey Nármer (o Aha), podría constituir un indicio de la existencia de alguna política de alianzas entre el expansivo Estado del Alto Egipto y otras zonas ya incorporadas o en proceso de incorporación a esa entidad política. En un sentido convergente, cf. Guksch 1992: 9; Menu 1996: 23; Savage 2001: 133-134. En todo caso, haya predominado el consenso o la coerción, el Estado podría haber concebido las tierras del norte que se integraban a sus dominios como "territorio conquistado" (cf. Wilkinson 1996: 96). 
CAMPAGNO, M. Los "proto-Estados" del Alto Egipto y la unificación del valle del Nilo. Rev. do Museu de Arqueologia e Etnologia, São Paulo, 12: 123-141, 2002.

\section{Cuadro cronológico}

\begin{tabular}{|c|c|c|c|c|}
\hline AÑOS a.C. & FASE & Entidades Políticas & & \\
\hline 3500 & Nagada IIb & & \multirow{6}{*}{$\begin{array}{l}\text { Escorpión I } \\
\text { Iry-Hor, } \\
\text { Escorpión II, Ka } \\
\text { Nármer } \\
\text { Aha } \\
\text { Dyer }\end{array}$} & \multirow{6}{*}{$\begin{array}{l}\text { "Halcón Doble" } \\
\text { serej de tres mazas } \\
\text { Ny-Hor, Hat-Hor } \\
\text { Cocodrilo, Ny-Neith }\end{array}$} \\
\hline 3400 & Nagada IIc & \multirow{2}{*}{$\begin{array}{l}\text { PROTO-ESTADOS DE } \\
\text { HIERACÓMPOLIS, } \\
\text { NAGADA Y ABIDOS }\end{array}$} & & \\
\hline 3300 & Nagada IId & & & \\
\hline 3200 & Nagada IIIa & \multirow{2}{*}{$\begin{array}{l}\text { PROTO-ESTADODEL } \\
\text { ALTOEGIPTO }\end{array}$} & & \\
\hline 3100 & Nagada IIIb & & & \\
\hline 3050 & Nagada IIIc & ESTADO UNIFICADO & & \\
\hline
\end{tabular}

CAMPAGNO, M. "Proto-States" of Upper Egypt and the unification of the Nile Valley. Rev. do Museu de Arqueologia e Etnologia, São Paulo, 12: 123-141, 2002.

ABSTRACT: The political unification of the Nile Valley, reached around 3.000 B.C., was the result of the expansion of State practices emerged in Upper Egypt about 3.400 B.C. Initially (Nagada IIc-d), three "proto-States" centered in Hierakonpolis, Nagada and Abydos appeared and, subsequently, they joined in a unique Upper Egyptian "proto-State". Besides, during the same time, the cultural influence of these centers would be expanded along the territory comprised from the First Cataract of the Nile to the Mediterranean Sea. In the next phase (Nagada IIIa-b), the cultural homogeneity of the Nile Valley would give way to the political integration, started with the territorial expansion of the southern "proto-State"

UNITERMS: Ancient Egypt-Proto-States-Unification of Egypt-Egyptian politics.

\section{Referencias bibliográficas}

\section{ABDEL-MONEIM, $\mathrm{M}$}

1996 Late Predynastic - Early Dynastic Mound of Beni Amir (Eastern Delta). L. Krzyzaniak; K. Kroeper; M. Kobusiewicz (Eds.) Interregional Contacts in the Later Prehistory of Northeastern Africa. Poznan. Poznan Archaeological Museum: 253-273.

ADAMS, $\mathrm{B}$.

1995 Ancient Nekhen. Garstang in the City of Hierakonpolis. New Malden: SIA Publishing.

ADAMS, B.

1996 Elite Tombs at Hierakonpolis. J. Spencer (Ed.) Aspects of Early Egypt. London, British Museum Press: 1-15.
ADAMS, B. ; CIALOWICZ, K.

1997 Protodynastic Egypt. Buckinghamshire: Shire Publications.

ANDELKOVIC, B.

1995 The Relations Between Early Bronze Age I Canaanites and Upper Egyptians. Belgrade,

BAINES, J. The University of Belgrade.

1991 Egyptian Mith and Discourse: Mith, Gods, and Early Written and Iconographic Record. Journal of Near Eastern Studies, 50: 81-105.

1995 Origins of Egyptian Kingship. D. O'Connor; D. Silverman (Eds.) Ancient Egyptian Kingship. Leiden, E. J. Brill: 95-156. 
CAMPAGNO, M. Los "proto-Estados" del Alto Egipto y la unificación del valle del Nilo. Rev. do Museu de Arqueologia e Etnologia, São Paulo, 12: 123-141, 2002.

BAKR, M.

1988 The New Excavations at Ezbet el-Tell, Kufur Nigm; The First Season 1984. E. Van den Brink (Ed.) The Archaeology of the Nile Delta. Problems and Priorities. Amsterdam, Netherlands Foundation for Archaeological Research: 49-62.

BARD, K.

1989 The Evolution of Social Complexity in Predynastic Egypt: An Analysis of the Naqada Cemeteries. Journal of Mediterranean Archaeology, 2: 223-248.

1994 From Farmers to Pharaohs. Mortuary Evidence for the Rise of Complex Society in Egypt. Sheffield: Sheffield Academic Press.

BAROCAS, C., FATTOVICH, R.; TOSI, M.

1989 The Oriental Institute of Naples Expedition to Petrie's South Town (Upper Egypt), 1977 1983: An Interim Report. L. Krzyzaniak; M. Kobusiewicz (Eds.) Late Prehistory of the Nile Basin and the Sahara. Poznan, Poznan Archaeological Museum: 295-301.

BRANDL, B

1992 Evidence for Egyptian Colonization of the Southern Coastal Plain and Lowlands of Canaan during the Early Bronze I Period. E. Van den Brink (Ed.) The Nile Delta in Transition. 4th-3rd. Millennium B.C. Tel Aviv, E. Van den Brink (publisher): 479-485.

BREWER, D.; WENKE, R.

1992 Transitional Late Predynastic - Early Dynastic Occupation at Mendes: A Preliminary Report. E. Van den Brink (Ed.) The Nile Delta in Transition. 4th-3rd. Millennium B.C. Tel Aviv, E. Van den Brink (publisher): 191-198.

\section{CAMPAGNO, M}

1998a Surgimiento del Estado en Egipto: Cambios y Continuidades en lo Ideológico. Buenos Aires, Universidad de Buenos Aires.

1998b God-kings and King-gods in Ancient Egypt. Ch. Eyre (Ed.) Proceedings of the Seventh International Congress of Egyptologysts. Leuven, Peeters: 237-243.

2001 Parentesco, intercambios, conflictos. Consideraciones sobre el surgimiento del Estado en Egipto. A. Daneri Rodrigo (Ed.) Relaciones de intercambio entre Egipto y el Mediterréneo Oriental (IV-I Milenio A.C.). Buenos Aires. Biblos: 13-31.

2002a De los jefes-parientes a los reyes-dioses. Surgimiento y consolidación del Estado en el Antiguo Egipto. Aula Ægyptiaca Studia 3. Barcelona, Aula Ægyptiaca.

$2002 b$ On the Predynastic "Proto-States" of Upper Egypt. Göttinger Miszellen, 188: 49-60.

CASE, H.; PAYNE, J.C.

1962 Tomb 100: The Decorated Tomb at Hierakonpolis. Journal of Egyptian Archaeology, 48: 5-18.

\section{CASTILLOS, $\mathbf{J}$}

1997 New Data on Predynastic Cemeteries. Revue d'Egyptologie, 48: 251-256.
CERVELLÓAUTUORI, J.

1996a Egipto y África. Origen de la civilización y la monarquía faraónicas en su contexto africano. Sabadell, Ausa.

1996b Egipto: Dinastía 0. Revista de Arqueología, 183: 6-15

CHLODNICKI, M.; FATTOVICH, R.; SALVATORII, S.

1992 The Nile Delta in Transition: A View from Tell el-Farkha. E.Van den Brink (Ed.) The Nile Delta in Transition. 4th-3rd. Millennium B.C. Tel Aviv, E. Van den Brink (publisher): 171-190.

CHLODNICKI, M.; CIALOWICZ, K.

2000 Tell el Farkha (Ghazala). Interim report, 1999 Polish Archaeology in the Mediterranean, 9: 59-76.

CIALOWICZ, $\mathrm{K}$

2001 La naissance d'un royaume. L'Egypte dès la période prédynastique à la fin de la lère dynastie. Krakow, Ksiegarnia Akademicka.

D'AMICONE, E.

1994 Le sepolture pre- e protodinastiche. A. Donadoni Roveri; E. D'Amicone; E. Leospo (Eds.) Gebelein. Il villaggio e la necropoli. Torino, Artema: 19-28.

\section{DARNELL, J.}

2002 Theban Desert Road Survey in the Egyptian Western Desert Vol. 1. Gebel Tjauti Rock Inscriptions 1-45 and Wadi el-Hol Rock Inscriptions 1-45. Oriental Institute Publications 119. Chicago, The Oriental Institute of the University of Chicago.

DARNELL, J.; DARNELL, D.

2000 The Theban Desert Road Survey (The LuxorFarshût Desert Road Survey). 1996-97 Annual Report (en Internet). Oriental Institute, University of Chicago.

DAVIS, W

1983 Cemetery T at Nagada. Mittelungen des Deutschen Archäologischen Instituts abteilung Kairo, 39: 17-28.

DREYER,G.

1992a Horus Kokodril, ein Gegenkönig der Dynastie 0 . R. Friedman; B. Adams (Eds.) The Followers of Horus. Studies dedicated to Michael Allen Hoffman, Oxford, Oxbow Books: 259-263.

1992b Recent Discoveries in the U-Cemetery at Abydos. E. Van den Brink (Ed.) The Nile Delta in Transition. 4th-3rd. Millennium B.C. Tel Aviv, E. Van den Brink (publisher): 293-300.

1998 Umm el-Qaab I. Das prädynastische Königsgrab $U$-j und seine frühen Schriftzeugnisse. Mainz, Verlag Philipp von Zabern.

DREYER, G. et al

1990 Umm el-Qaab. Nachuntersuchungen im frühzeitlichen Königsfriedhof. 3.14. Vorbericht. Mitteilungen des Deutschen Archäologischen Instituts abteilung Kairo, 46: 53-90.

1993 Umm el-Qaab. Nachuntersuchungen im frühzeitlichen Königsfriedhof. 5./6. Vorbericht. 
CAMPAGNO, M. Los "proto-Estados" del Alto Egipto y la unificación del valle del Nilo. Rev. do Museu de Arqueologia e Etnologia, São Paulo, 12: 123-141, 2002.

Mitteilungen des Deutschen Archäologischen Instituts abteilung Kairo, 49: 23-62.

EIGNER, D.

2000 Tell Ibrahim Awad: Divine Residence from Dynasty 0 until Dynasty 11. Ägypten und Levante, 10: 17-36.

ELLIS, Ch

1992 A Statistical Analysis of the Protodynastic Burials in the "Valley" Cemetery of Kafr Tarkhan. E. Van den Brink (Ed.) The Nile Delta in Transition. 4th-3rd. Millennium B.C. FALTINGS, D Tel Aviv, E. Van den Brink (publisher): 241-248.

1998 New Light on the Chronological Frame of the Buto-Maadi Culture (Abstract). Simposio Egyptian - Canaanite Interaction: From the $4^{\text {th }}$ to the $3^{\text {rd }}$ Millennium B.C. E., Jerusalem.

\section{FATTOVICH, $R$}

1984 Remarks on the Dynamics of State Formation in Ancient Egypt. Wiener Beiträge zur Ethnologie und Anthropologie, 1: 29-78.

\section{FINKENSTAEDT, E.}

1984 Violence and Kingship: The Evidence of the Palettes. Zeitschrift fur die Ägyptische Sprache und Altertumskunde, 111: 107-110.

\section{FISCHER, $\mathrm{H}$.}

1963 Varia Aegyptiaca. Journal of the American Research Center in Egypt, 2: 17-51.

FRIED, $M$

1978 The State, the Chicken, and the Egg: or, What Came First? R. Cohen; E. Service (Eds.) Origins of the State, Philadelphia, Institute for the Study of Human Issues: 35-48.

\section{FRIEDMAN, $R$.}

1992 The Early Dynastic and Transitional Pottery of Mendes: The 1990 Season. E. Van den Brink (Ed.) The Nile Delta in Transition. 4th3rd. Millennium B.C. Tel Aviv, E. Van den Brink (publisher): 199-206.

1996 The Ceremonial Centre at Hierakonpolis: Locality HK29A. J. Spencer (Ed.) Aspects of Early Egypt. London, British Museum Press: 16-35.

GALASSI, G.

1955 L'arte del più Antico Egitto nel Museo di Torino. Rivista dell'Istituto Nazionale d'Archeologia e Storia dell'Arte (NS), 4: 5-94.

GELLER, J

1992 From Prehistory to History: Beer in Egypt. R. Friedman; B. Adams (Eds.) The Followers of Horus. Studies dedicated to Michael Allen Hoffman. Oxford, Oxbow Books: 19-26.

GOPHNA, R.

1990 The Early Bronze I Settlement at 'En Besor Oasis. Israel Exploration Journal, 40: 1-11. GRISWOLD, W.

1992 Measuring Social Inequality at Armant. R. Friedman; B. Adams (Eds.) The Followers of Horus. Studies dedicated to Michael Allen Hoffman. Oxford, Oxbow Books: 193-198.
GUKSCH, Ch.

1992 On Ethnographic Analogies. R. Friedman; B.

Adams (Eds.) The Followers of Horus.

Studies dedicated to Michael Allen Hoffman. Oxford, Oxbow Books: 7-10.

GUNDLACH, $R$.

1998 Der Pharao und sein Staat. Die Grundlegung der ägyptischen Königsideologie im 4. Und

3. Jahrtausend. Darmstadt: Wissenschaftliche Buchgessellschaft.

HARTUNG, U.

1998 Prädynastiche Siegelabrollungen aus dem Friedhof $\mathrm{U}$ in Abydos (Umm el-Qaab). Mittelungen des Deutschen Archäologischen Instituts abteilung Kairo, 54: 188-217.

HASSAN, F.

1988 The Predynastic of Egypt. Journal of World Prehistory, 2: 135-185.

2000 Kafr Hassan Dawood. Egyptian Archaeology, 16: 37-39.

\section{HENDRICKX, $\mathrm{S}$.}

2001 Arguments for an Upper Egyptian Origin of the Palace-façade and the Serekh during Late Predynastic - Early Dynastic times. Göttinger Miszellen, 184: 85-110.

HOFFMAN, $M$.

1979 Egypt before the Pharaoh. New York: Barnes \& Noble.

HOFFMAN, M. (Ed.)

1982a The Predynastic of Hierakonpolis. Cairo: Cairo University Herbarium

HOFFMAN, M.; HAMROUSH, H.; ALLEN, R.

1986 A Model of Urban Development for the Hierakonpolis Region from Predynastic through Old Kingdom Times. Journal of the American Research Center in Egypt, 23: 175187.

HOFFMAN, M.; LUPTON, C.; ADAMS, B.

1982 Excavations at Locality 6. M. Hoffman (Ed.) The Predynastic of Hierakonpolis. Cairo: 38-60.

KAISER, W.; DREYER, G.

1982 Umm el-Qaab. Nachuntersuchungen im frühzeitlichen Königsfriedhof. 2. Vorbericht. Mitteilungen des Deutschen Archäologischen Instituts abteilung Kairo, 38: 211-269.

KEMP, B.

1973 Photographs of the Decorated Tomb at Hierakonpolis. Journal of Egyptian Archaeology, 59: 36-43.

1977 The Early Development of Towns in Egypt. Antiquity, 51: 185-200.

1992 El Antiguo Egipto. Anatomía de una [1989] civilización. Barcelona: Crítica.

KÖHLER,Ch

1992 The Pre- and Early Dynastic Pottery of Tell el-Fara' in (Buto). E. Van den Brink (Ed.) The Nile Delta in Transition. 4th-3rd. Millennium B.C. Tel Aviv, E. Van den Brink (publisher): 11-22.

1999 Re-Assessment of a Cylinder Seal from Helwan. Göttinger Miszellen, 168: 49-56. 
CAMPAGNO, M. Los "proto-Estados" del Alto Egipto y la unificación del valle del Nilo. Rev. do Museu de Arqueologia e Etnologia, São Paulo, 12: 123-141, 2002.

KÖHLER, Ch.; VAN DEN BRINK, E.

2002 Four Jars with Incised Serekh-Signs from Helwan Recently Retrieved from the Cairo Museum. Göttinger Miszellen, 187: 59-81.

KROEPER, $\mathrm{K}$.

1986-87 The Ceramic of the Pre/Early Dynastic Cemetery of Minshat Abu Omar. Bulletin of the Egyptological Seminar, 8: 73-94.

1988 The Excavations of the Munich East-Delta Expedition in Minshat Abu Omar. E. Van den Brink (Ed.) The Archaeology of the Nile Delta. Problems and Priorities. Amsterdam, Netherlands Foundation for Archaeological Research: 11-19.

1992 Tombs of the Elite in Minshat Abu Omar. E. Van den Brink (Ed.) The Nile Delta in Transition. 4th-3rd. Millennium B.C. Tel Aviv, E. Van den Brink (publisher): 127-150.

LEVY Th. etal.

1997 Egyptian-Canaanite Interaction at Nahal Tillah, Israel (ca. 4500-3000 B.C.E.): An Interim Report on the 1994-1995 Excavations. Bulletin of the American School of Oriental Research, 307: 1-51.

LOVELL, N.

1997 The 1995 Excavations of the Cemetery at Kafr Hassan Daoud, Wadi Tumilat. Journal of the Society for the Study of Egyptian Antiquities, 27:34-41.

MAISELS, Ch.

1999 Early Civilizations of the World. The Formative Histories of Egypt, The Levant, Mesopotamia, India and China. London: Routledge.

MARK, S

1998 From Egypt to Mesopotamia. A Study of Predynastic Trade Routes. London: Chatham Publishing.

MENU, B.

1996 Naissance du pouvoir pharaonique. Méditerranées, 6/7: 17-59.

MIDANT-REYNES, B.

1992 Préhistoire de l'Égypte. Des premiers hommes aux premiers Pharaons. Paris: Armand Colin.

MONNET-SALEH, J.

1986 Interpretation globale des documents concernant l'unification de l'Egypte. Partie I. Bulletin de l'Institut Français d'Archeologie Orientale, 86: 227-238.

1990 Interpretation globale des documents concernant l'unification de l'Egypte. Partie II. Bulletin de l'Institut Français d'Archeologie Orientale, 90: 259-279.

\section{MORTENSEN, B.}

1991 Change in the Settlement Pattern and Population in the Beginning of the Historical Period. Ägypten und Levante, 2: 11-37.

\section{NORDSTRÖM, $\mathrm{H}$}

1972 The Early Nubian Cultures. T. Säve-Soderbergh (Ed.) Neolithic and A-Group Sites. Uppsala,
The Scandinavian Joint Expedition to Sudanese Nubia Publications: 17-32.

O'CONNOR, D.

1993 Ancient Nubia. Egypt's Rival in Africa. Philadelphia, The University Museum.

\section{REDFORD, D.}

1983 Notes on the History of Ancient Buto. Bulletin ot the Egyptological Seminar, 5: 67101.

RIZKANA, I.; SEEHER, J.

1987 Maadi I. The Pottery of the Predynastic Settlement. Mainz: Verlag Philipp von Zabern.

1990 Maadi IV. The Predynastic Cemeteries of Maadi and Wadi Digla. Mainz: Verlag Philipp von Zabern.

SAVAGE, $S$.

1997 Descent Group Competition and Economic Strategies in Predynastic Egypt. Journal of Anthropological Archaeology, 16: 226-268.

2001 Some Recent Trends in the Archaeology of Predynastic Egypt. Joumal of Archaeological Research, 9: 101-155.

\section{SCHMIDT, $\mathrm{K}$.}

1992 Tell el'Fara' in/Buto and el-Tell el-Iswid (south): The Lithic Industries from the Chalcolithic to the Early Old Kingdom. E. Van den Brink (Ed.) The Nile Delta in Transition. 4th-3rd. Millennium B.C. Tel Aviv, E. Van den Brink (publisher): 31-41.

SEEHER, J.

1992 Burial Customs in Predynastic Egypt: A View from the Delta. E. Van den Brink (Ed.) The Nile Delta in Transition. 4th-3rd. Millennium B.C. Tel Aviv, E. Van den Brink (publisher): 225-234.

\section{SEIDLMAYER, $S$.}

1996 Town and State in the Early Old Kingdom: A View from Elephantine. J. Spencer (Ed.) Aspects of Early Egypt. London, British Museum Press: 108-127.

\section{TUTUNDZIC, $S$}

1993 A Consideration of Differences between the Pottery Showing Palestinian Characteristics in the Maadian and Gerzean Cultures. Journal of Egyptian Archaeology, 79: 33-55.

\section{VAN DEN BRINK, E}

1989 A Transitional Late Predynastic-Early Dynastic Settlement Site in the Northeastern Nile Delta, Egypt. Mittelungen des Deutschen Archäologischen Instituts abteilung Kairo, 45: 55-108.

1992 Preliminary Report on the Excavations at Tell Ibrahim Awad, Seasons 1988-1990. Van den Brink, E. (Ed.) The Nile Delta in Transition. 4th-3rd. Millennium B.C. Tel Aviv, E. Van den Brink (publisher): 43-68.

1996 The Incised Serekh-Signs of Dynasties 0-1, Part I: Complete Vessels. J. Spencer (Ed.) Aspects of Early Egypt. London, British Museum Press: 140-158. 
CAMPAGNO, M. Los "proto-Estados" del Alto Egipto y la unificación del valle del Nilo. Rev. do Museu de Arqueologia e Etnologia, São Paulo, 12: 123-141, 2002.

\author{
VANDIER, J. \\ 1952 Manuel d'Archeologie Égyptienne. Paris: \\ Editions A. et J. Picard. \\ VERCOUTTER, J. \\ 1992 L'Égypte et la vallée du Nil. Tome I: Des \\ origines à la fin de l'Ancien Empire 12000 - \\ 2000 av. J.C. Paris, Presses Universitaires de \\ France. \\ 1994 Or et Politique dans l'Égypte des Origines. C. \\ Berger; G. Clerc; N. Grimal (Eds.) Hommages à \\ Jean Leclant, Vol. 2. Le Caire, Institut \\ Français d'Archéologie Orientale: 403-410. \\ VON DER WAY, Th. \\ 1992 Excavations at Tell el-Fara' in/Buto in 1987- \\ 1989. E. Van den Brink (Ed.) The Nile Delta in \\ Transition. 4th-3rd. Millennium B.C. Tel \\ Aviv, E. Van den Brink (publisher): 1-10.
}

Recebido para publicação em 14 de novembro de 2002.

\section{WILKINSON, T.}

1996 State Formation in Egypt. Chronology and Society. Cambridge Monographs in African Archaeology, vol. 40. BAR International Series 651. Oxford: Tempus Reparatum.

1999 Early Dynastic Egypt. London: Routledge.

2000 Political Unification: Towards a Reconstruction. Mitteilungen des Deutschen Archäologischen Instituts abteilung Kairo, 56: 377-395.

\section{WILLIAMS, B.}

1982 Notes on Prehistoric Cache Fields of Lower Egyptian Tradition at Sedment. Journal of Near Eastern Studies, 41: 213-221.

1986 The A-Group Royal Cemetery at Qustul: Cemetery $L$. Chicago, The Oriental Institute of the University of Chicago.

1988 Narmer and the Coptos Colossi. Journal of the American Research Center in Egypt, 25: 35-59. 